\title{
Intermittent African Easterly Wave Activity in a Dry Atmospheric Model: Influence of the Extratropics
}

\author{
STEPHANIE LEROUX \\ NOAA/ESRL/PSD, Boulder, Colorado \\ NiCHOLAS M. J. HALL \\ LEGOS, Universite Paul Sabatier, Toulouse, France \\ GEORGE N. KILADIS \\ NOAA/ESRL/PSD, Boulder, Colorado
}

(Manuscript received 21 January 2011, in final form 12 May 2011)

\begin{abstract}
A dynamical model is constructed of the northern summertime global circulation, maintained by empirically derived forcing, based on the same dynamical code that has recently been used to study African easterly waves (AEWs) as convectively triggered perturbations (Thorncroft et al.; Leroux and Hall). In the configuration used here, the model faithfully simulates the observed mean distributions of jets and transient disturbances, and explicitly represents the interactions between them. This simple GCM is used to investigate the origin and intraseasonal intermittency of AEWs in an artificially dry (no convection) context. A long integration of the model produces a summertime climatology that includes a realistic African easterly jet and westward-propagating 3-5-day disturbances over West Africa. These simulated waves display intraseasonal intermittency as the observed AEWs also do. Further experiments designed to discern the source of this intermittency in the model show that the simulated waves are mainly triggered by dynamical precursors coming from the North Atlantic storm track. The model is at least as sensitive to this remote influence as it is to local triggering by convective heating.
\end{abstract}

\section{Introduction}

On synoptic scales, African easterly waves (AEWs) are the dominant mode of atmospheric variability over West Africa in summer (June-September). AEWs are baroclinic westward-propagating disturbances observed in convective and dynamical fields, with wavelengths of about $3000-6000 \mathrm{~km}$ and periods of 3-5 days [see Kiladis et al. (2006) for a recent composite study]. They appear as intermittent wave packets on intraseasonal time scales. A large range of studies have already highlighted and investigated their coupling with convection (e.g., Kiladis et al. 2006), their role in modulating mesoscale convective system activity and precipitation (e.g., Duvel 1990; Diedhiou et al. 1999; Gu et al. 2004, 2003; Fink and

Corresponding author address: Stephanie Leroux, R/PSD1, NOAA/ESRL, 325 Broadway, Boulder, CO 80305-3328.

E-mail: stephanie.leroux@noaa.gov
Reiner 2003), and their possible connection to total seasonal rainfall (Grist 2002; Nicholson et al. 2008).

The question of the origin and intermittency of AEWs has been a lively topic of discussion in the recent literature. A better understanding of the mechanisms modulating AEW activity would be helpful for forecasting purposes-in the West African region because of the association of the waves with convection and precipitation but also in the tropical Atlantic region, since AEWs are seen as precursors of many tropical depressions and cyclones developing off the West African coast (e.g., Avila and Pasch 1992; Thorncroft and Hodges 2001; Berry and Thorncroft 2005).

Theories on the origin of AEWs have become considerably more complex since the pioneering studies by Burpee (1972) and colleagues in the 1970s. AEWs were first suggested to arise from barotropic and baroclinic instability on the African easterly jet (AEJ). Since then, the general view has broadened to include interactions 
between the AEWs, the AEJ, and convection. The feedback of convection onto the dynamical waves has been much emphasized because this is thought to contribute to an amplification of the waves as they propagate (e.g., Cornforth et al. 2009; Hsieh and Cook 2008). Convection also appears to play a role in the establishment and maintenance of the waves' environment and source of energy (in particular the AEJ) and thus probably influences its variability at time scales longer than the wave period, within a season (e.g., Cornforth et al. 2009; Hsieh and Cook 2008; Thorncroft and Blackburn 1999; Schubert et al. 1991).

In addition to these relationships between convection and the waves in their mature stage, convection is also thought to directly influence their initiation. A series of papers has recently called into question the "pure instability" view and reemphasized Carlson's (1969) suggestion of convective initiation of the waves over orography east of the AEJ. Hall et al. (2006) show in a normal-mode study based on a three-dimensional climatological basic state that a realistic amount of surface damping neutralizes the AEJ. They argue that even though the structure of the first normal mode found for the three-dimensional AEJ is very similar to the real AEWs, its growth rate is very small or even negative. The growth of random infinitesimal disturbances on an unstable AEJ cannot explain the presence of waves with a realistic amplitude in the short time they spend within the jet. Hall et al. instead promote the idea that an initial finite amplitude perturbation is needed as a trigger. They show in a companion modeling study that the heating from a strong convective event in the upstream part of the AEJ, such as over the Darfur mountains, could play the role of the trigger (Thorncroft et al. 2008). This triggering hypothesis opens new and interesting perspectives to explain the intermittency of AEWs, suggesting a possible modulation of the wave activity by factors other than the AEJ itself.

There is observational evidence for the convective triggering hypothesis. Mekonnen et al. (2006) show a statistical link on interannual time scales between convection in the upstream region of the jet and AEW activity. A few case studies, such as one focusing on the AEW precursor of Hurricane Alberto in 2000 (Berry and Thorncroft 2005), also highlight a strong burst of convection to the east, over the Darfur mountains, preceding the wave. On intraseasonal time scales, Leroux et al. (2010) point out a statistical association of increased convection in that area prior to increased AEW activity.

However, the convective triggering hypothesis does not provide a comprehensive explanation for the initiation and intraseasonal variability of the waves, first, because this only transforms the problem to one of understanding of the occurrence of the convective triggering events. Second, the evidence of an increase of convection prior to AEW events is only shown on the basis of statistical analyses and a few case studies, and it does not verify clearly for every observed wave event. The intermittency of AEWs may in reality result from a combination of different types of finite amplitude initial perturbations, either convective or remote in origin, and modulated by more or less favorable conditions of the environment (e.g., Leroux and Hall 2009).

Some recent studies have promoted the influence of the midlatitudes on the summertime West African dynamics. Vizy and Cook (2009) proposed a mechanism by which African monsoon breaks could be attributable to cold air surges coming through the Mediterranean. Chauvin et al. (2010) investigated the intraseasonal variability of the Saharan heat low (SHL) by analyzing the 850-hPa potential temperature modes of variation over northern Africa. Their results suggest that the main mode of SHL variability could be driven by the southeastward penetration of midlatitude Rossby wave disturbances over Europe and northern Africa. The impact of this mechanism on Sahelian convection variability is investigated further in Roehrig et al. (2011). Interestingly, Chauvin et al. (2010) also showed that the main SHL mode is concomitant with a westward-propagating signal of enhanced convection from the Chad-Sudan region to the Atlantic coast. The authors thus suggested that the midlatitude wave train they detected might modulate AEW activity.

In this paper we consider the idea that midlatitude transient activity might be an alternative source of triggering disturbances for AEWs. We explore this hypothesis using a model of intermediate complexity, covering the gap between idealized models and full GCMs (e.g., Hoskins 1983; Hall 2004). Our model is based on the dry full primitive equations, and part of its solution is forced by the observations: a time-independent forcing term is derived from the data to represent the time-mean effect of all the physical processes that are not included in the model equations (i.e., mainly the diabatic forcing). Such models can be run efficiently for long, GCM-like integrations and are useful tools that allow for the full nonlinear dynamics of the atmosphere while simplifying the physical parameterizations of the system (convection and precipitation in particular). Hall (2000) set up such a dry T21 spectral model forced by a time-mean diabatic term derived for the winter season. Both the time-mean fields and the transient eddy covariances are shown to be realistically simulated at the global scale.

Lin et al. (2007) used the same model at higher resolution (T31) and analyzed wintertime intraseasonal variability. They focused mainly on a large-scale eastwardpropagating signal in the tropics that they identified as 
a Kelvin wave and highlighted the influence of the midlatitudes on the forcing of these waves. With a similar model, Sardeshmukh and Sura (2007) also addressed the question of the role of the variable part of the diabatic forcing versus its time-dependent part on the global atmospheric circulation, and Yasui and Watanabe (2010) investigated the so-called circumglobal teleconnection during summer. All these studies found a reasonable simulation of the mean state along with realistic transient eddy activity.

Here we force the model with a mean diabatic term derived from climatological northern summer conditions. Our objective is to specifically investigate the synoptic intraseasonal variability over West Africa in a precipitationfree context that still retains the full nonlinear global atmospheric circulation. Are AEWs simulated in such a modeling setup? To what extent does the variability of the AEJ-AEW system remain similar to the observed when convection is removed? What accounts for AEW initiation and intermittency in this dry context? Unlike previous perturbation modeling studies with fixed basic states (Hall et al. 2006; Leroux and Hall 2009) or the zonally uniform jets studied by Thorncroft (1995) and Cornforth et al. (2009), our simulations contain transients that can fully interact with a realistic three-dimensional AEJ. The main simplification remains that a constant diabatic forcing is applied and that transient convective processes are ignored. In this way we investigate some potential alternative initial disturbances for AEWs.

In section 2 the model, the simulations, and the data used for this study are presented. Section 3 briefly shows some of the global features of our main ("standard") simulation. Section 4 focuses on West Africa and demonstrates that realistic intermittent AEWs are simulated by the dry model. Section 5 investigates in more detail the origin of the simulated waves and highlights the remote influence of transient activity from the North Atlantic storm track. These results are summarized and discussed in section 6 .

\section{Model, data, and methods}

\section{a. The model}

The model used for this study is a dry (no moisture) global spectral primitive equation model based on the atmospheric global circulation model of the University of Reading (Hoskins and Simmons 1975), which has been developed and used in various settings, forcing configurations, and contexts since then (e.g., Thorncroft and Hoskins 1994; Hall 2000; Lin et al. 2007; Leroux and Hall 2009).

The horizontal spectral resolution is set here to T31, and there are 10 equally spaced vertical levels in $\sigma$ coordinates. The full nonlinear equations for vorticity, divergence, temperature, and $\log$ (surface pressure) are integrated with a semi-implicit 22.5 -min time step. The vertical scheme conserves mass, energy, and angular momentum based on the method of Simmons and Burridge (1981). There is a $12-\mathrm{h} \nabla^{6}$ diffusion of momentum and temperature that accounts for enstrophy cascade to unresolved scales. A low-level linear damping is also applied to represent in a simple manner the turbulent transfers of momentum and heat with the surface: at the two lowest levels of the model, the momentum damping has a time scale of 2 days (level $\sigma=0.85$ ) and 0.67 day (level $\sigma=0.95$ ), while the temperature damping has time scales of 4 and 1.34 days at these two levels, respectively. For the upper levels, the time scale of this damping is set to 30 days for momentum and 10 days for temperature. Other than these, the model contains no physical parameterizations.

We use the model in the same forcing configuration as in Hall (2000), Hall and Derome (2000), and Lin et al. (2007): the model is free to develop its own transient activity and to reach its own dynamical equilibrium state. This is achieved by applying an empirically derived timeindependent forcing to all the model variables at all the levels, following a method first proposed by Roads (1987) and used in various studies with different models since then (e.g., Marshall and Molteni 1993; Lin and Derome 1996; Sardeshmukh and Sura 2007). These time-independent three-dimensional forcing functions are evaluated by integrating the primitive equation model (including the damping terms) for one time step from a sequence of observed states, and then averaging all the tendencies. Here we derive the forcing from the daily June-September 1979-2006 National Centers for Environmental Prediction/Department of Energy Global Reanalysis 2 (NCEP-2). This time-independent forcing term can be seen as representing the mean effect of all the processes that are not explicitly included in the model equations, that is, primarily the mean diabatic forcing (Hall 2000).

Provided that the damping added to the primitive equations is linear and acts locally, this specified forcing can also be seen to be equivalent to the "restoration forcing" often used in simpler idealized studies. In these studies a state variable is "restored" linearly toward an equilibrium profile, which may be far from any observed or model state. Here we do not specify any restoration profile, but rather we specify the damping time scales and deduce the forcing objectively from data.

\section{b. Data}

The initial state and the time-independent forcing are prepared from the daily NCEP-2 data (Kanamitsu et al. 2002). The daily June-September 1979-2006 data have 
been spectrally analyzed at T31 and interpolated to give vorticity, divergence, and temperature on the 10 equally spaced sigma levels of the model. A time-heightindependent divergence correction has been applied, as outlined by Hall (2000), to take into account possible vertical interpolation errors. Orography is not represented explicitly in the model, so surface pressure is calculated by the integration of the barometric equation from the $1000-\mathrm{mb}$ height to 0 using the $1000-\mathrm{mb}$ temperature. It should be pointed out that the time-mean effect of orography is still indirectly accounted for through the forcing.

\section{c. Standard and nudged simulations}

We perform one main simulation that we refer to as the standard simulation, which consists of a 4000-day integration of the model forced with the time-independent forcing term derived from the June-September 19792006 NCEP-2 data.

We also perform some nudged simulations in section 5. These have exactly the same setting as the standard simulation except that in one specific area of the globe, the zonal and meridional components of the wind are nudged toward their model climatological values (defined as the time-mean values of the standard run). This nudging is applied at every grid point of the designated area and at every time step. Its strength is set by a timescale coefficient $\tau=6 \mathrm{~h}$, which is short enough to damp most of the transient activity that would have developed in this area in the standard configuration. The objective of the nudging is here to maintain the model state close to its climatological state within the nudged area while artificially suppressing any transient activity there. For the rest of the globe (which is not nudged), the model is free to develop transient activity as in the standard simulation. A buffer zone of 1 grid point is applied around the nudged area, where the nudging is half the strength. Four different nudged simulations corresponding to four different nudged areas will be discussed: 1) north of $30^{\circ} \mathrm{N}, 2$ ) south of the equator, 3) north of $30^{\circ} \mathrm{N}$ and south of $10^{\circ} \mathrm{S}$, and 4) east of $45^{\circ} \mathrm{E}$ in the Northern Hemisphere.

\section{d. Analyses}

Each simulation (standard and nudged) lasts 4000 days but only the last 3416 days are analyzed to discard the spinup period. Various diagnostics of the mean state of the model and its transient activity are calculated and compared with the corresponding diagnostics in the NCEP-2 data that we take here as our reference. Intraseasonal time scales and AEW frequencies are isolated using 0-120- or 0-10-day Lanczos filters, respectively, with 61 weights (Duchon 1979). Lag regressions are computed as in Leroux et al. (2010), by correlating spatial fields of interest at each grid point with a single time series (here, an "AEW activity index"; see section 5) for successive time lags. The perturbations obtained are scaled to one standard deviation of the index. The results shown here are locally statistically significant at the $95 \%$ level after taking into account temporal autocorrelation between the reference time series and the gridpoint fields (Livezey and Chen 1983). A two-sided significance test was performed to assess local significance, assuming the distribution of the correlation coefficient is "normal" with a standard deviation of $1 / \sqrt{n-3}, n$ being the actual number of temporal degrees of freedom (Wilks 2005).

\section{Global view of the model climatology and transient activity for summertime}

In this study, our main interest is to concentrate on West Africa. However, we first show a few basic diagnostics of the standard simulation at the global scale, to make a link with the previous literature using this category of model. Further discussion of the performance and limitations of such models can be found in Hall (2000) and Hall and Derome (2000) (same model as we use here) or in Sardeshmukh and Sura (2007) (with a different model).

We note that most of the previous studies have focused on simulations of the boreal winter, while the summer season has received less attention (see, for instance, Yasui and Watanabe 2010).

\section{a. Mean state}

Figure 1 compares the time-mean state of our summertime simulation with the June-September 19792006 climatology from the NCEP-2 data (i.e., the period of observations used to derive the constant forcing). The zonal wind is shown at level $\sigma=0.25$ (approximately $250 \mathrm{hPa}$ ) in the left panels and on a zonally averaged latitude-height section in the right panels. In the Northern Hemisphere, the model reproduces well the upper-level jets in the midlatitudes, with two main jet cores over both the North American-North Atlantic area and over Asia at about $40^{\circ} \mathrm{N}$. As already found by Hall (2000) or Sardeshmukh and Sura (2007), their magnitude is slightly overestimated. The model also simulates realistic easterlies in the northern tropics, peaking both over the Indian Ocean and east of Central America. In the Southern Hemisphere, it reproduces relatively well the main jet core along $35^{\circ} \mathrm{N}$ from Australia to the east Pacific. But it also produces some less realistic maxima in zonal wind over South America and South Africa. 
(a) NCEP2 clim. Jun-Sept. 1979-2006 : U $250 \mathrm{hPa}$

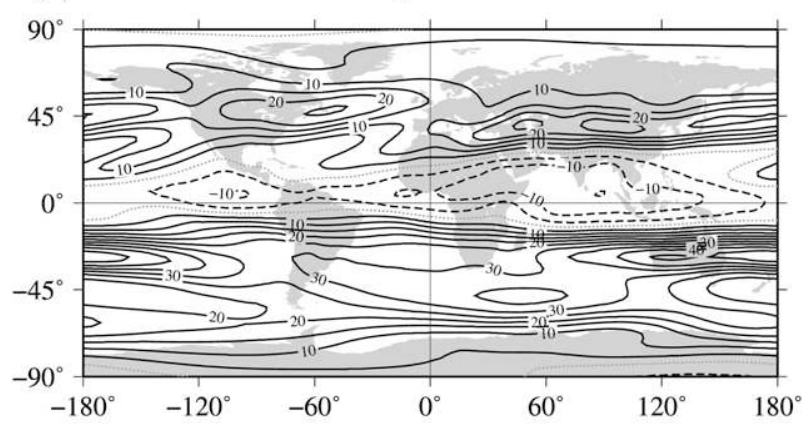

(c) Model clim. (std simulation) : U $250 \mathrm{hPa}$

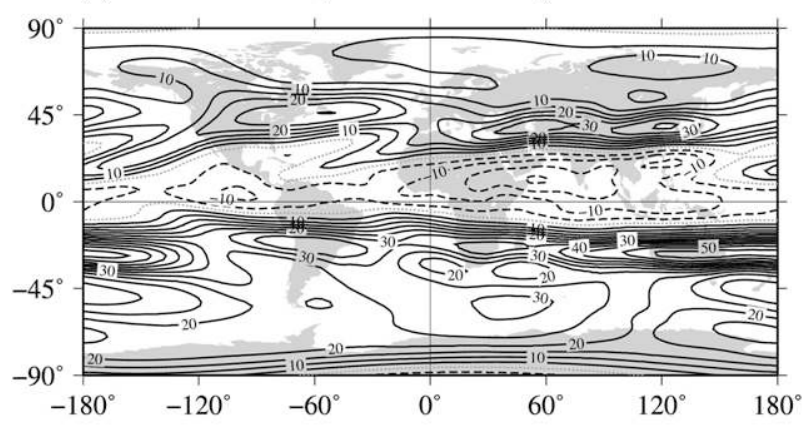

(b) NCEP2 clim. zonal mean

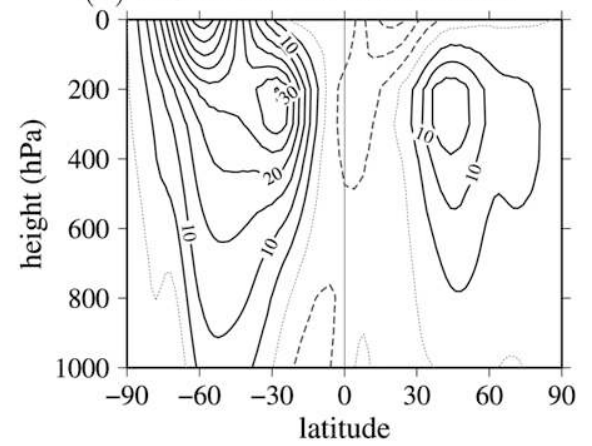

(d) Model clim. zonal mean

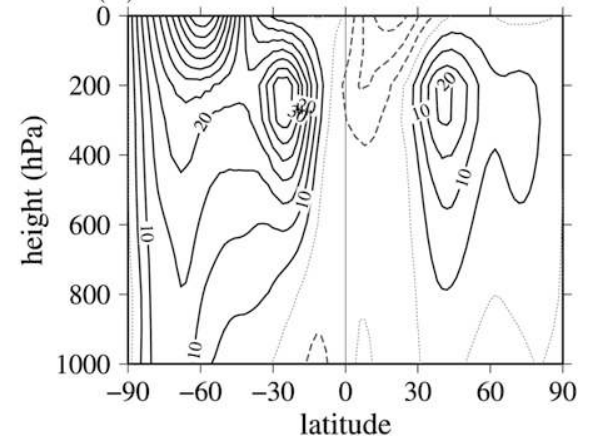

FIG. 1. Climatological zonal wind (a),(c) at $250 \mathrm{hPa}$ and (b),(d) on the latitude-height zonal mean section. (top) June-September 1979-2006 NCEP-2 data, and (bottom) mean state of standard simulation. Contours every $5 \mathrm{~m} \mathrm{~s}^{-1}$. Negative values dashed, and zero contour dotted.

\section{b. Transient activity}

Figure 2 now compares some diagnostics of the simulated transient activity with the reanalyses. Figures $2 a, b$ and Figs. 2c,d show the covariance fluxes of momentum $\overline{u^{\prime} v^{\prime}}$ and temperature $\overline{v^{\prime} T^{\prime}}$ at 250 and $850 \mathrm{hPa}$, respectively, and Figs. 2e,f show eddy kinetic energy (EKE)

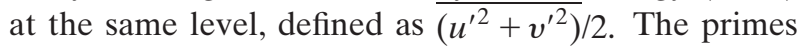
denote a 0-120-day filter, which retains only the intraseasonal variability. Overbars denote a time average over the entire time series. For all these quantities, the model shows realistic global patterns, with simulated transient activity mainly collocated with the midlatitude jets. The poleward heat flux at these latitudes is consistent, for instance, with the development of baroclinic waves on the jets. As found in previous studies, the model fails to produce enough transient activity, especially in the EKE. This discrepancy seems even greater in our summertime simulation than it is for the winter season in the previous studies. To better illustrate this point, we can compare more precisely with Sardeshmukh and Sura (2007), who evaluate the average EKE at each level for their wintertime simulation over all longitudes north of $20^{\circ} \mathrm{N}$. At $250 \mathrm{hPa}$ they find that this quantity is about 1.5 times smaller in their model than in the reanalyses (see their Fig. 9). Such a ratio was found to be of the same order as in some full-physics GCM simulations. However, in the summertime simulation we are presenting here, the same diagnostic gives a ratio of about 4.5. To put this result into context, we have also performed a wintertime simulation with our model where we obtained a ratio of 1.8 , consistent with Sardeshmukh and Sura (2007). Such a difference between the two seasons is not mentioned by Yasui and Watanabe (2010). Further work beyond the scope of the present study would be needed before drawing any more general interpretation. But following Sardeshmukh and Sura's (2007) discussion, this discrepancy between summertime and wintertime simulations might illustrate a stronger role in summer of the variable part of the diabatic forcing in producing the variability in the Northern Hemisphere.

\section{Results from the West African region}

In this section we first present the model climatology over West Africa, focusing on the main features of the regional summertime climate. Then we demonstrate the presence of synoptic-scale transient activity in the region that has many of the observed characteristics of African easterly waves. 
(a) NCEP2 $250 \mathrm{hPa} \overline{u^{\prime} v^{\prime}}$

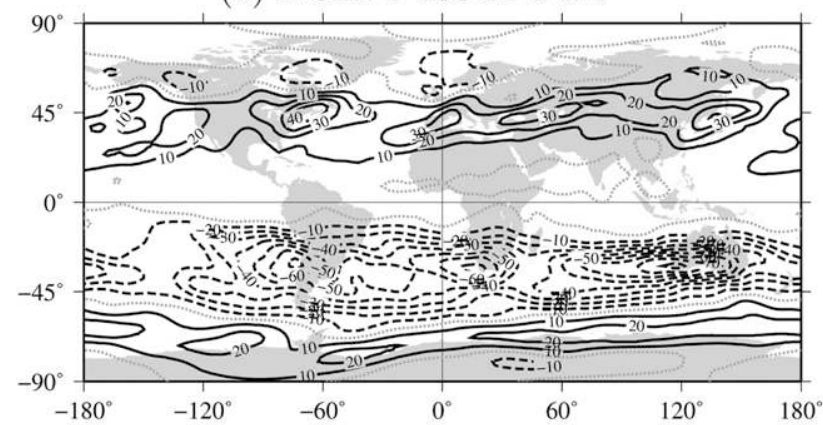

(c) NCEP2 $850 \mathrm{hPa} \overline{v^{\prime} T^{\prime}}$

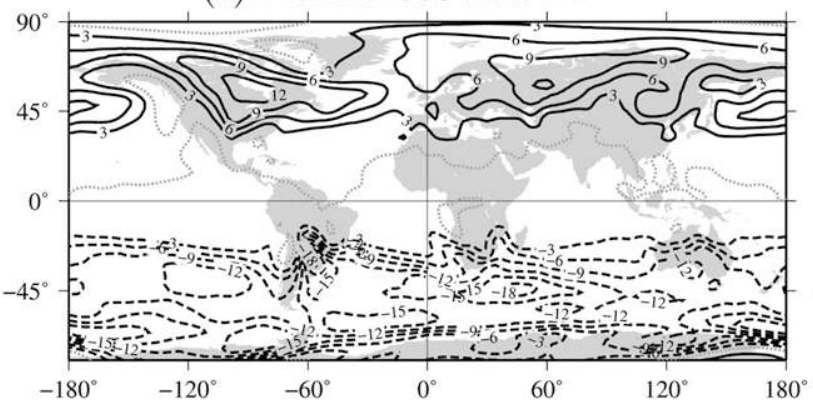

(e) NCEP2 $250 \mathrm{hPa}$ EKE

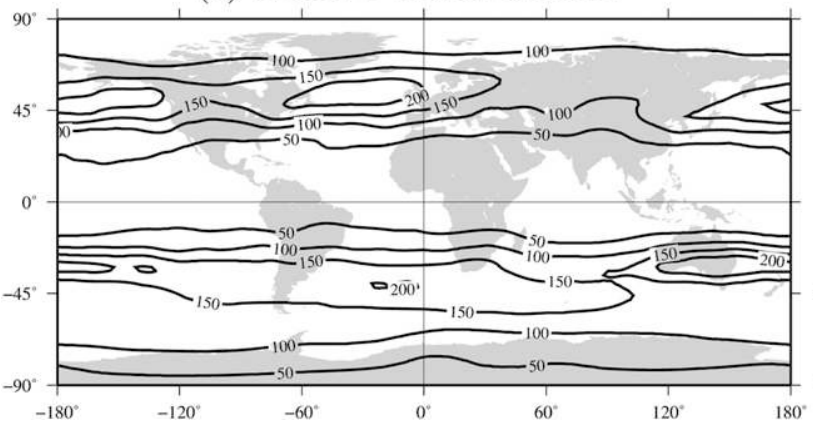

(b) Std Sim. $250 \mathrm{hPa} \overline{u^{\prime} v^{\prime}}$

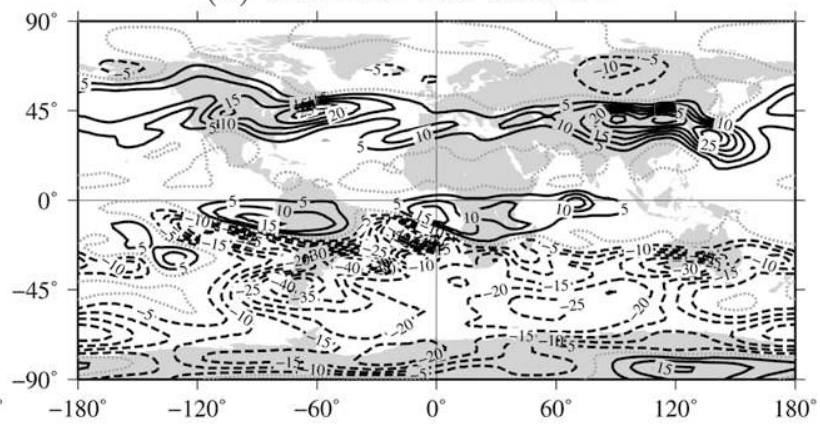

(d) Std Sim. $850 \mathrm{hPa} \overline{v^{\prime} T^{\prime}}$

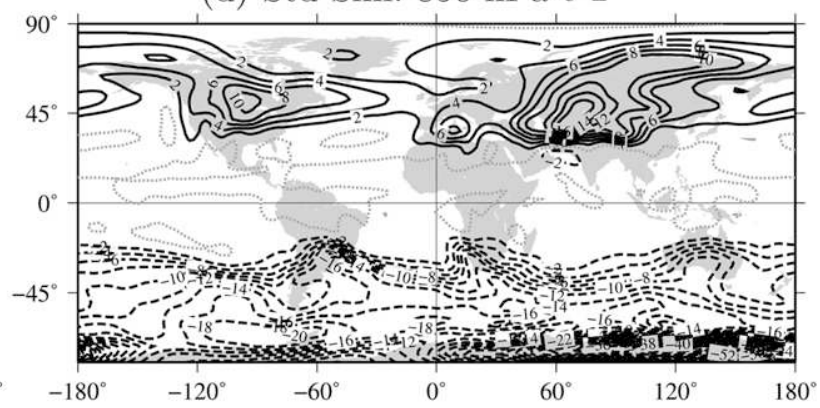

(f) Std Sim. $250 \mathrm{hPa}$ EKE

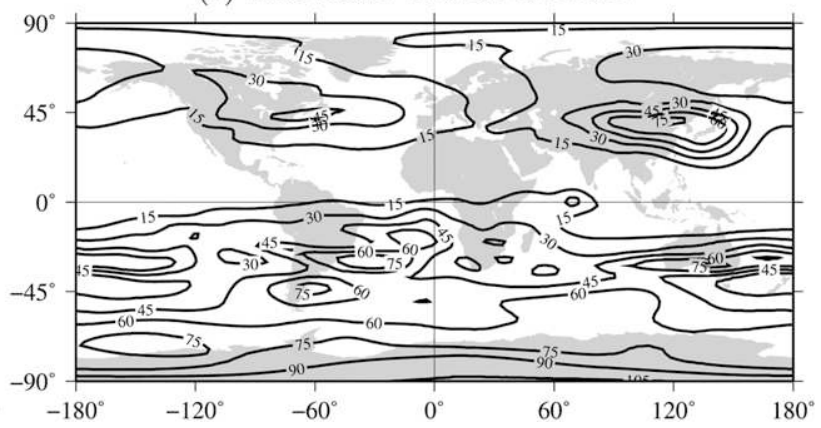

FIG. 2. Covariance fluxes and EKE of the transients of $<120$ days. (left) June-September 1979-2006 NCEP-2 data, and (right) standard simulation. (a),(b) At $250 \mathrm{hPa}, \overline{u^{\prime} v^{\prime}}$ momentum flux contours every 10 and $5 \mathrm{~m}^{2} \mathrm{~s}^{-2}$; (c),(d) $\overline{v^{\prime} T^{\prime}}$ temperature flux at $850 \mathrm{hPa}$, contours every 3 and $2 \mathrm{~K}^{-1} \mathrm{~m} \mathrm{~s}^{-1}$; (e),(f) EKE at $250 \mathrm{hPa}$ (see text for definition), contours every 50 and $15 \mathrm{~m}^{2} \mathrm{~s}^{-2}$. Negative values dashed, and zero contour dotted.

\section{a. West African mean state}

Figure 3 compares our model climatology over West Africa with the June-September 1979-2006 climatology from the NCEP-2 data. The zonal wind at $650 \mathrm{hPa}$ is shown in the left panels. The latitude-height section along the Greenwich meridian is shown in the right panels.

The AEJ is a major feature of the West African atmospheric dynamics in summer, and its zonal wind shear is an important component in the energy budget for AEWs. The model simulates a mean jet that is very similar to the observed climatological AEJ. The jet peaks at $10 \mathrm{~m} \mathrm{~s}^{-1}$ at about $650 \mathrm{hPa}$ and $12^{\circ} \mathrm{N}$, and the easterly winds greater than $8 \mathrm{~m} \mathrm{~s}^{-1}$ extend from about $40^{\circ} \mathrm{W}$ to $15^{\circ} \mathrm{E}$ in both the reanalyses and the model. However, some weaker easterlies persist further to the east in the model, extending as far as the north of India.

The other important features of the West African climate are also well simulated: the tropical easterly jet (TEJ) at about $250 \mathrm{hPa}$ and $10^{\circ} \mathrm{N}$, and the surface south westerlies over the continent, from the equator up to $20^{\circ} \mathrm{N}$. In the vertical section along the Greenwich meridian, the TEJ and the midlatitude jet $\left(35^{\circ} \mathrm{N}\right)$ appear to be stronger by a few meters per second in the model than they are in the reanalyses, consistent with what was already noted for zonal wind at upper levels on the global scale (Fig. 1).

Figure 3 also shows the standard deviation of the 0-120-day filtered zonal wind at the level of the AEJ. In 
(a) NCEP2 clim. Jun-Sept. 1979-2006 : U 650 hPa

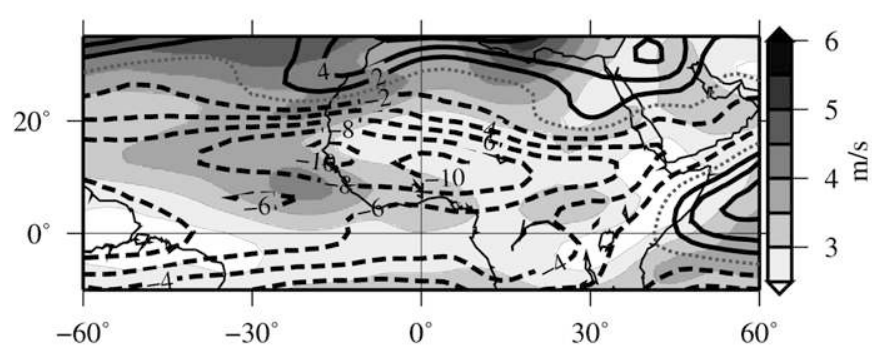

(c) Model clim. (std simulation) : U $650 \mathrm{hPa}$

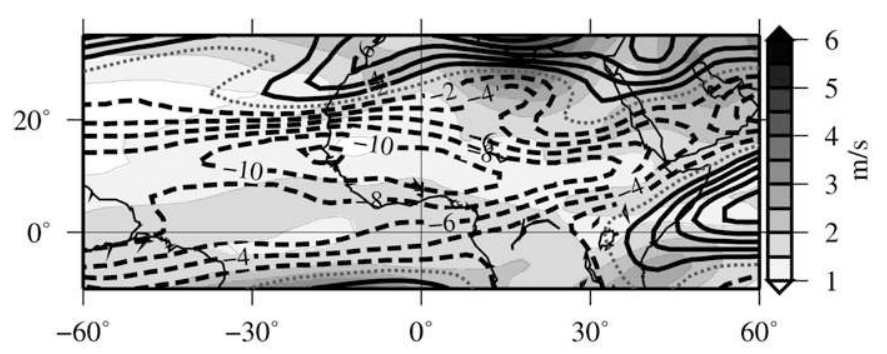

(b) NCEP2 clim. along 0E

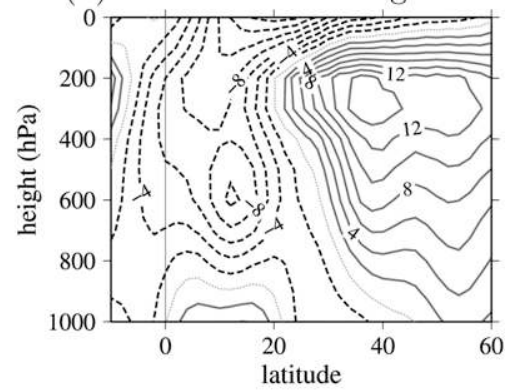

(d) Model clim. along $0 \mathrm{E}$

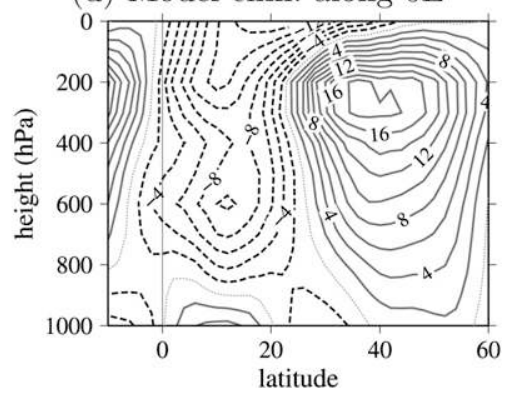

FIG. 3. Climatological zonal wind over West Africa (a),(c) at $650 \mathrm{hPa}$ and (b),(d) on a latitude-height section along the Greenwich meridian. (top) June-September 1979-2006 NCEP-2 data, and (bottom) average of standard simulation. Contours every $2 \mathrm{~m} \mathrm{~s}^{-1}$. Negative values dashed, and zero contour dotted. Standard deviation shaded every $0.5 \mathrm{~m} \mathrm{~s}^{-1}$ starting at (a) 2.5 and (c) $1.0 \mathrm{~m} \mathrm{~s}^{-1}$.

the reanalyses, the standard deviation is at a maximum on the flanks of the jet on its downstream part, while the simulated zonal wind shows weaker variability on the jet's flanks. East of the Greenwich meridian, however, in the upstream part of the AEJ, a maximum of standard deviation over the Mediterranean Basin extending to northern Africa around $15^{\circ} \mathrm{E}$ is seen both in the model and in the reanalyses. Some further spatial empirical orthogonal function (EOF) analyses performed on the zonal wind at $650 \mathrm{hPa}$ in the West African region (not shown) also confirmed that the variability is better simulated in the upstream part of the AEJ, east of Greenwich, than in the downstream part.

\section{b. African easterly waves}

We now concentrate specifically on the synoptic-scale transient activity. Figures $4 a$,b shows Hovmoeller diagrams of the meridional wind anomaly at $850 \mathrm{hPa}$ between $30^{\circ} \mathrm{W}$ and $30^{\circ} \mathrm{E}$ for two 120 -day samples of the standard simulation, calculated by removing the climatological mean without any other filtering applied. Clear westward-propagating anomalies of alternating sign are seen with an approximate period of 5 days, similar to how the observed AEWs appear in Figs. 4c,d. The horizontal structure of these simulated waves is shown in Fig. 5, where the streamfunction at $850 \mathrm{hPa}$ is regressed against the less than 10-day filtered meridional wind at base point $9.5^{\circ} \mathrm{N}, 7.5^{\circ} \mathrm{W}$ for successive time lags. At day 0 a positive (anticyclonic) anomaly can be seen, flanked by two negative (cyclonic) anomalies, the stronger over the Atlantic coast. In a couple of days, the succession of cyclonic and anticyclonic anomalies, with a wavelength of about $3500 \mathrm{~km}$, moves westward and attenuates after passing the coast. This horizontal structure and scale compare well with the observed lagged composite shown by Kiladis et al. (2006). They also compare well with the decaying modal structures found on a three-dimensional climatological basic state in Hall et al. (2006). This similarity is consistent with the idea that any finite amplitude precursors will naturally lead to decaying modal forms, as already shown and discussed for heating-triggered AEWs in Thorncroft et al. (2008) and Leroux and Hall (2009).

Looking again at the Hovmoeller diagrams (Fig. 4), we note that the amplitude of the strongest waves in the model is in the range of $\pm 3 \mathrm{~m} \mathrm{~s}^{-1}$, whereas the same diagrams from the reanalyses display waves about twice as large. The weakness of the simulated waves is undoubtedly partly due to the lack of convective heating in the model, which as discussed above has been shown to be a significant energy source for both the genesis and growth of real easterly waves. However, it is noteworthy that the amplitude of the strongest simulated anomalies in the standard simulation is about 3 times greater than the amplitude of the waves that can be triggered by 
(a) 120-day sample of the std simulation (b) 120-day sample of the std simulation
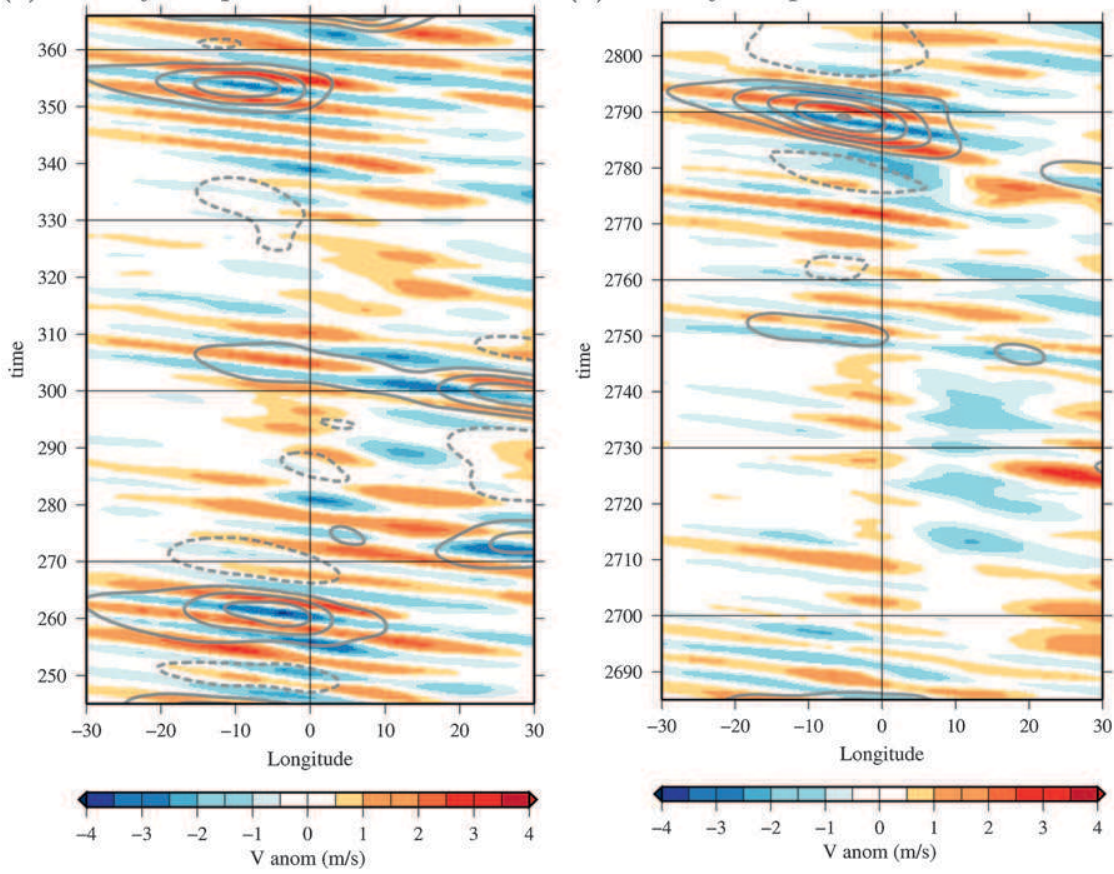

(c) JJAS 2001 NCEP2
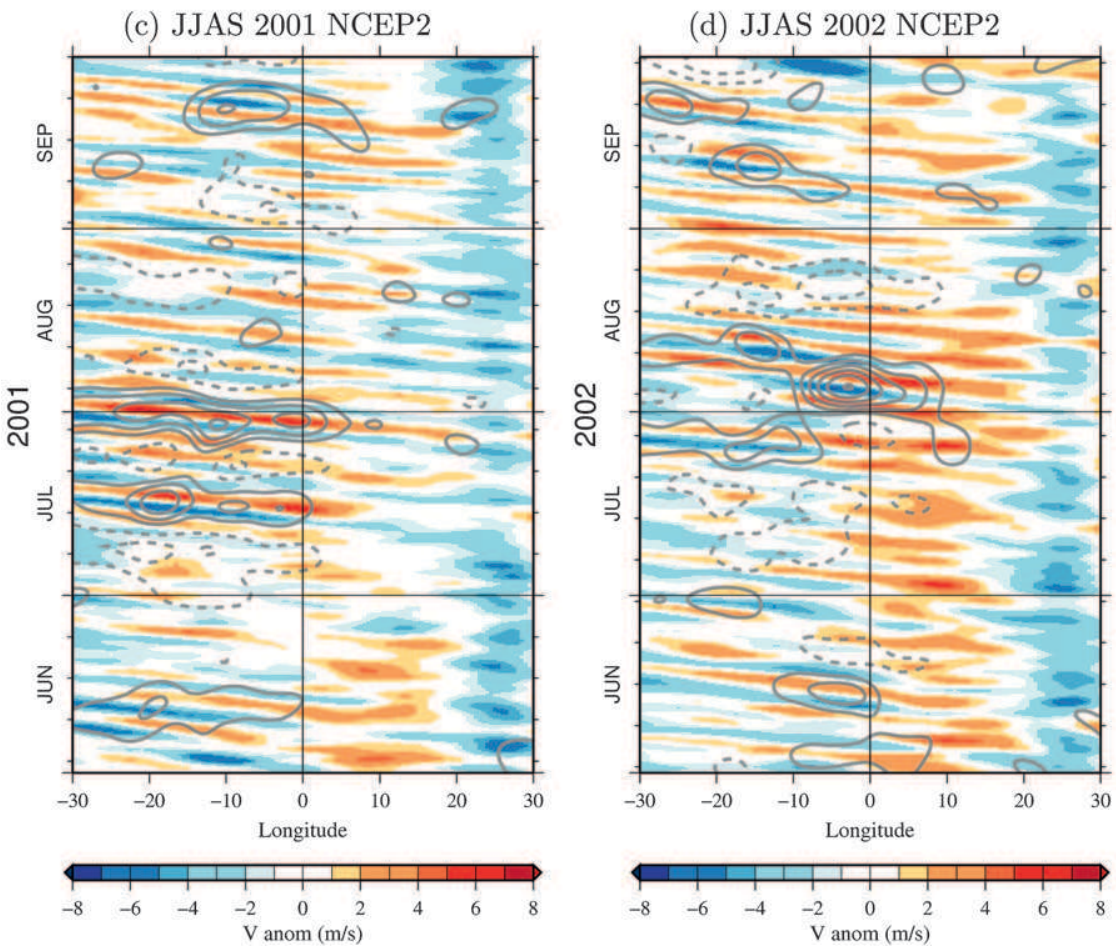

FIG. 4. Hovmoeller (time-longitude) diagram averaged over $5^{\circ}-20^{\circ} \mathrm{N}$ of 120 -day samples of the meridional wind anomaly (shading; climatological mean removed) and 10-120-day filtered EKE (also see text) at $850 \mathrm{hPa}$ from (a),(b) the standard simulation (climatological mean removed) and (c),(d) NCEP-2 data. Contours for EKE are every $0.7 \mathrm{~m}^{2} \mathrm{~s}^{-2}$ in (a),(b) and every $3 \mathrm{~m}^{2} \mathrm{~s}^{-2}$ in (c),(d). Negative values dashed, and zero contour omitted. 


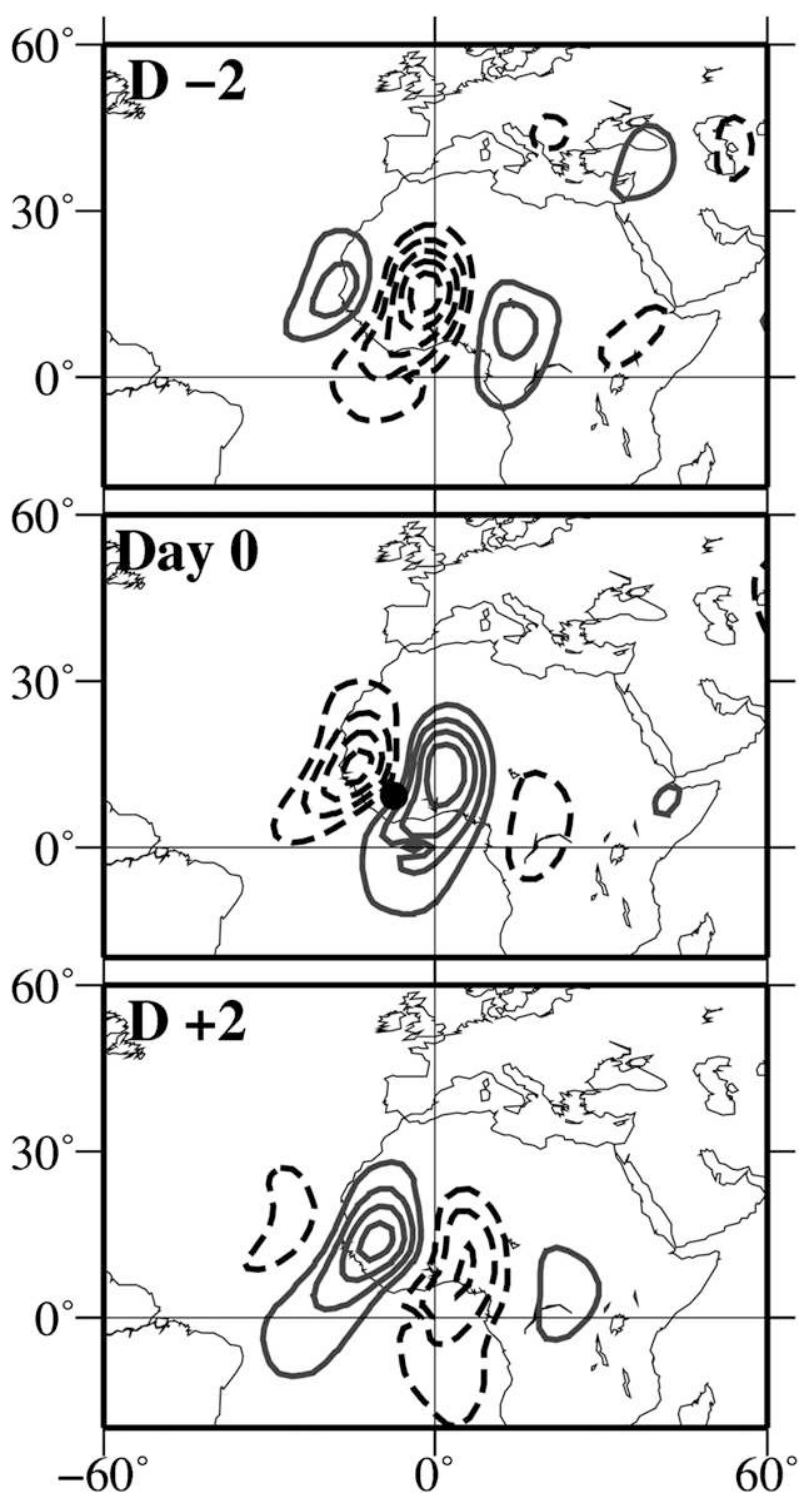

FIG. 5. Composite AEW horizontal structure in the standard simulation: Regression of the 0-120-day filtered 850 -hPa streamfunction onto the $0-10$-day filtered meridional wind at base point $9.5^{\circ} \mathrm{N}, 7.5^{\circ} \mathrm{W}$ (black circle shown at day 0 ) for time lags of (top to bottom) $-2,0$, and +2 days. Contours every $1.5 \mathrm{~m}^{2} \mathrm{~s}^{-2}$. Negative values dashed, and zero contour omitted.

heating in the jet entrance on a fixed climatological basic state, following previous perturbation studies by Thorncroft et al. (2008) and Leroux and Hall (2009).

Finally, what is perhaps even more striking in Fig. 4 is the variability in wave activity. This appears as intermittency in the occurrence of the wave packets, as for real AEWs. For example, in the first 120-day sample (Fig. 4a), a first relatively strong wave packet is seen from about day 255 to day 268, followed by a period of weaker activity. Another wave packet is seen from day 300 to day 310 , and a third wave packet after day 340 .
This intermittency is representative of what can be seen in the rest of the simulation. However, less active periods can last several consecutive months (as seen on the second 120-day sample, Fig. 4b), which is generally not observed for real AEWs. A reason for this could be that, by design, our simulation does not account for any variability in AEW activity that could come from intermittent convection. Only dry sources for intermittency are considered here, so we expect to miss at least this part of AEW intermittency. Describing in more detail the statistical nature of this intermittency, in both the observation and the model, is beyond the scope of this study. Here we just point out that even a dry model is able to simulate AEW-like perturbations with "some" intermittency, of which we aim to investigate the source(s) in the following section.

Figure 6 shows similar EKE and covariance flux diagnostics as in Fig. 2 but focused this time on West Africa. As already seen on the global scale, the magnitude of the transient activity is weaker in the model than in the reanalyses. In the NCEP-2 data, the EKE of the transients less than 10 days at $850 \mathrm{hPa}$ peaks at about $5 \mathrm{~m}^{2} \mathrm{~s}^{-2}$ over the African-Atlantic coast, giving another indication of AEW activity in the area. The model reproduces this pattern but with an amplitude about 5.5 times weaker (ratio obtained from the $850-\mathrm{hPa}$ EKE spatially averaged in the box $2^{\circ}-24^{\circ} \mathrm{N}, 30^{\circ} \mathrm{W}-15^{\circ} \mathrm{E}$ ), and its location is also shifted a bit to the east (over the continent) compared to the reanalyses. However, at this point it is important to emphasize that large discrepancies also exist for this EKE quantity over West Africa (both in amplitude and location of the maximum) between the various full-physics GCM of the Intergovernmental Panel on Climate Change (IPCC), and even between the NCEP reanalysis and the European Centre for Medium-Range Weather Forecasts Re-Analysis (ERA), as shown in the recent study by Ruti and Dell'Aquila (2010).

The momentum and temperature covariance fluxes (Figs. 6a-d) show patterns relatively similar to the reanalyses but again with a weaker magnitude. Despite their small amplitude, they are still consistent with the development of baroclinic waves on the AEJ, with the transient heat flux going down the regional meridional temperature gradient. We conclude that, overall, despite the fact that the model has weaker-than-observed transients, they are located in the correct place, consistent with what is known about their dry dynamics in relation to the AEJ.

\section{Origin of the simulated AEW activity}

\section{a. Nudged simulations}

The set of diagnostics shown in the previous section make the point that the model contains some dynamical 
(a) NCEP2 $650 \mathrm{hPa} \overline{u^{\prime} v^{\prime}}(<10 \mathrm{~d})$

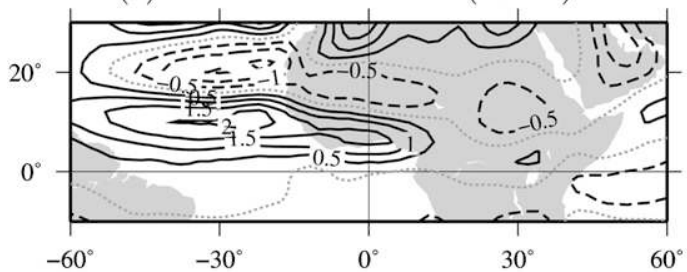

(c) NCEP2 $850 \mathrm{hPa} \overline{v^{\prime} T^{\prime}}(<10 \mathrm{~d})$

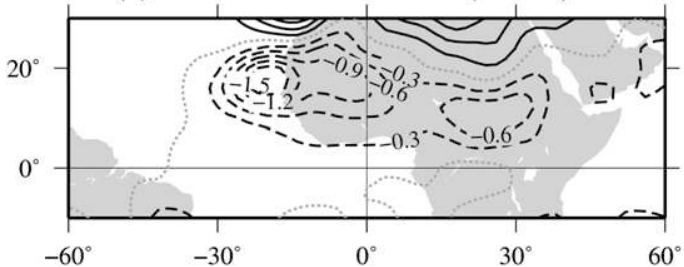

(e) NCEP2 $850 \mathrm{hPa} \operatorname{EKE}(<10 \mathrm{~d})$

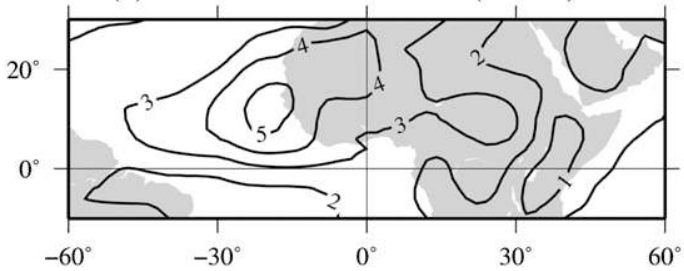

(b) Std Sim. $650 \mathrm{hPa} \overline{u^{\prime} v^{\prime}}(<10 \mathrm{~d})$

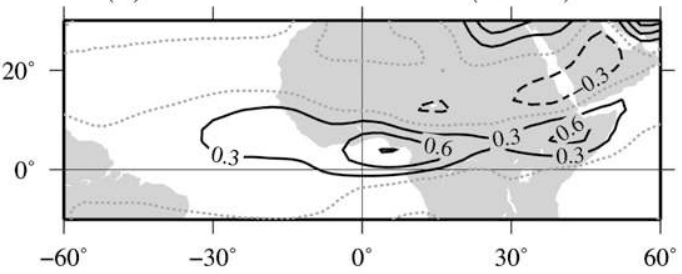

(d) Std Sim. $850 \mathrm{hPa} \overline{v^{\prime} T^{\prime}}(<10 \mathrm{~d})$

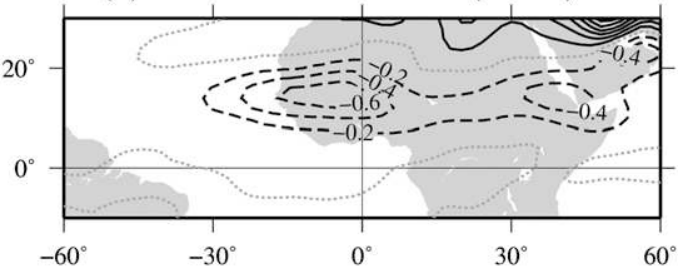

(f) Std Sim. 850 hPa EKE (<10 d)

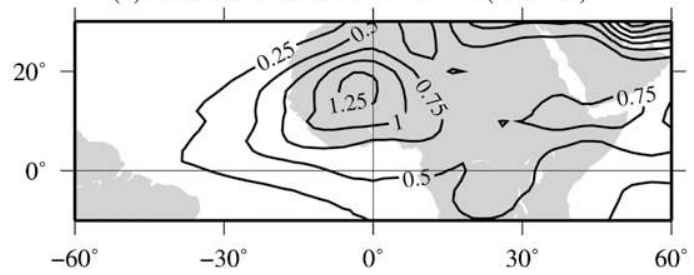

FIG. 6. Covariance fluxes and EKE of the transients less than 10 days over West Africa. (left) June-September 1979-2006 NCEP-2 data, and (right) standard simulation. (a),(b) At $650 \mathrm{hPa}, \overline{u^{\prime} v^{\prime}}$ momentum flux contours every 0.5 and $0.3 \mathrm{~m}^{2} \mathrm{~s}^{-2}$; (c),(d) $\overline{v^{\prime} T^{\prime}}$ temperature flux at $850 \mathrm{hPa}$, contours every 0.3 and $0.2 \mathrm{~K}^{-1} \mathrm{~m} \mathrm{~s}^{-1}$; and (e),(f) EKE at $850 \mathrm{hPa}$ (see text for definition), contours every 1 and $0.25 \mathrm{~m}^{2} \mathrm{~s}^{-2}$. Negative values dashed, and zero contour dotted.

mechanisms to generate and maintain intermittent dry AEWs. In this dry modeling setup though, the simulated AEWs cannot be explained by intermittent convective triggering.

To investigate the alternative source for the waves diagnosed in the standard simulation, we conduct some further-nudged-simulations, as presented in section 2. The nudging technique is here used to suppress the transient activity in a specific remote region of the model to assess what influence that has on the simulated AEWs.

Figure 7 summarizes the different simulations performed. The left column shows the model time-mean zonal wind at $250 \mathrm{hPa}$ and the mean EKE at the same level for transients with a period of less than 120 days. Because of the nudging applied in the chosen area, the model state stays very close to the control climatology (defined from the standard simulation) in that zone. Outside the nudged area, the transient activity is still fairly similar to the standard simulation, and the mean zonal wind does not change much either. It is important to emphasize that West Africa and more generally the entire tropical band between the equator and $30^{\circ} \mathrm{N}$ is free to develop transient activity in all the simulations. Furthermore, the climatological AEJ (upon which
AEWs develop) is always present and does not change much from one simulation to another (Fig. 7, right column).

To evaluate the presence or absence of AEWs in the different nudged experiments, we look again at the EKE of the transients with periods of less than 10 days at $850 \mathrm{hPa}$ (shading in Fig. 7, right column). For a quantitative comparison, the value of 850-hPa EKE spatially averaged in the box $2^{\circ}-24^{\circ} \mathrm{N}, 30^{\circ} \mathrm{W}-15^{\circ} \mathrm{E}$ is also reported for the five experiments (Fig. 7, above each right panel).

Figure 7a shows the results from the standard simulation (already shown in Fig. 6f): A maximum of EKE appears over West Africa centered around $15^{\circ} \mathrm{N}, 5^{\circ} \mathrm{W}$ as a signature of the simulated AEWs. It can be seen in Fig. $7 \mathrm{c}$ that nudging the model toward its climatology in the Southern Hemisphere (i.e., suppressing the transient activity) does not affect the maximum of EKE over West Africa very much. AEWs are still produced, and this has also been verified in Hovmoeller diagrams (not shown). In contrast, Fig. $7 \mathrm{~b}$ clearly shows that suppressing the transient activity north of $30^{\circ} \mathrm{N}$ has a strong impact on the simulated AEW activity. The maximum in EKE over West Africa has disappeared (Hovmoeller 
(a)

Std run

(b)

Nudged

north of

$30^{\circ} \mathrm{N}$

(c)

Nudged
south of
the
Equator

(d)

Nudged north of

$30^{\circ} \mathrm{N}$ and

south of

$10^{\circ} \mathrm{S}$

(e)

Nudged

east of

$45^{\circ} \mathrm{E}$

in the

northern $-45^{\circ}$

hemisphere
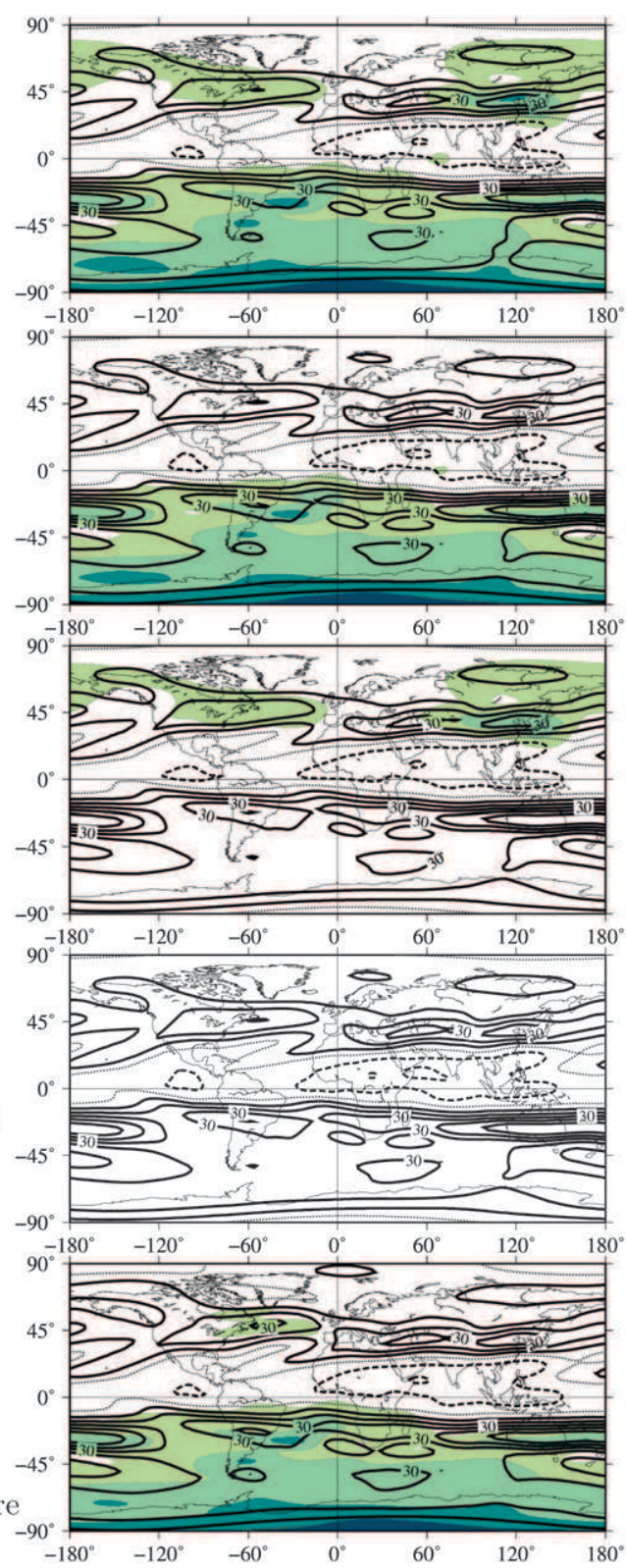

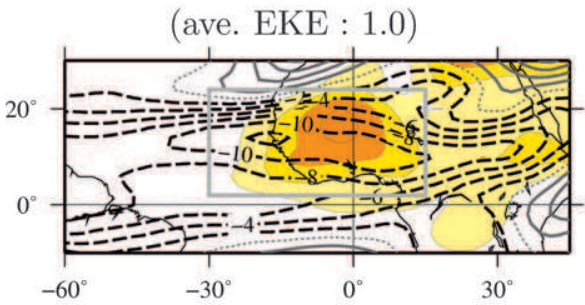

(ave. EKE : 0.26)

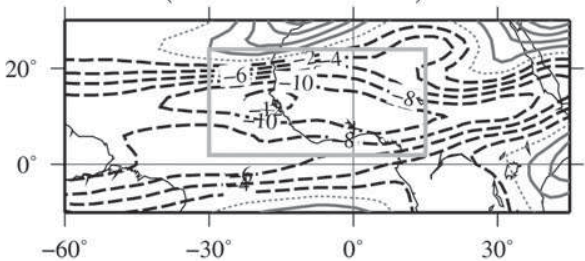

(ave. EKE : 0.83)

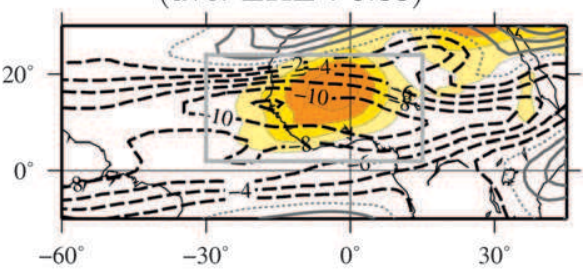

(ave. EKE : 0.0)

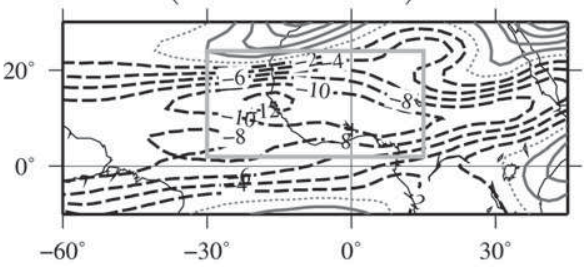

(ave. EKE : 0.69)

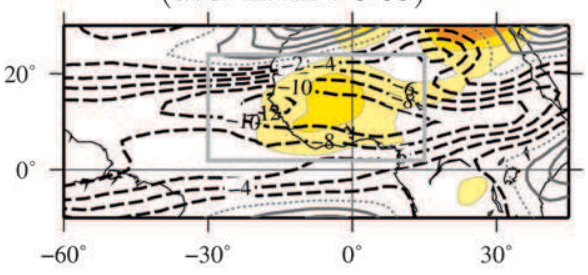

FIG. 7. (left) Time-mean model zonal wind (contours every $10 \mathrm{~m} \mathrm{~s}^{-1}$ ) and EKE of transients of $<120$ days (shading every $25 \mathrm{~m}^{2} \mathrm{~s}^{-2}$ starting at 25) at $250 \mathrm{hPa}$. (right) Time-mean model zonal wind (contours every $2 \mathrm{~m} \mathrm{~s}^{-1}$ ) and EKE of transients of $<10$ days (shading every $0.25 \mathrm{~m}^{2} \mathrm{~s}^{-2}$ starting at 0.5 ) at $850 \mathrm{hPa}$ over West Africa. (a) Standard simulation. (b)-(e) Simulations nudged: (b) north of $30^{\circ} \mathrm{N}$, (c) south of the equator, (d) north of $30^{\circ} \mathrm{N}$ and south of $10^{\circ} \mathrm{S}$, and (e) east of $45^{\circ} \mathrm{E}$ in the Northern Hemisphere. Also given for each simulation is the value of the $850-\mathrm{hPa}$ EKE spatially averaged in the rectangle shown in the right column $\left(2^{\circ}-24^{\circ} \mathrm{N}, 30^{\circ} \mathrm{W}-15^{\circ} \mathrm{E}\right)$ and normalized by the value in (a). For comparison, the same normalized value in the NCEP-2 data is 5.5.

diagrams again confirm that no significant AEWs are produced in this simulation). The complementary experiment (Fig. 7d) combining nudging in both the Southern Hemisphere and the area north of $30^{\circ}$ gives, as expected, a similar result: no AEWs simulated. The last experiment (Fig. 7e), in which the transient activity is suppressed only in the Asian jet area (Northern
Hemisphere between $45^{\circ} \mathrm{E}$ and $180^{\circ}$ ), gives an intermediate result: A maximum in EKE is still present over West Africa but is weaker than in the standard experiment.

At this point, two main results can be highlighted. 1) The initiation of intermittent AEWs in the model does not occur locally near the AEJ. If this were the case, then 
suppressing the transient activity outside of West Africa would not affect their initiation, especially because a realistic climatological AEJ is present in all the experiments and does not vary much from one simulation to another. 2) If the simulated waves are not a result of local instability of the AEJ, then this implies that a trigger originating in a remote area is needed. And since the model is dry, this must be a dynamical triggering mechanism. The experiments indicate that, in the model, transient activity in the North Atlantic storm track provides the primary trigger for African waves.

\section{b. Sequences of events prior to simulated AEW activity}

To gain more insight into how AEWs are dynamically triggered in the dry model, we present the results of a regression analysis of the 0-120-day filtered streamfunction and zonal wind fields from the standard simulation onto an index of the simulated AEW activity. We define a perturbation kinetic energy index, following Leroux et al. (2010), as

$$
\mathrm{AEW}_{\text {index }}=\left(\overline{\frac{u^{\prime 2}+v^{\prime 2}}{2}}\right) .
$$

Primes denote a 0-10-day filter and the overbar denotes a 10-120-day filter, retaining only the intraseasonal variations in wave activity for time scales greater than the waves themselves. The "wave activity" quantity inside the brackets is plotted on the Hovmoeller diagrams in Fig. 4 for illustration: its fluctuations are consistent with the wave packets appearing in the meridional wind anomalies. A spatial average (denoted by the brackets above) is then done over the area $5^{\circ}-24^{\circ} \mathrm{N}, 11^{\circ} \mathrm{W}-19^{\circ} \mathrm{E}$ to get the AEW activity index.

Since it was concluded in section 5a that the main source of excitation of AEW in the model comes from the Northern Hemisphere, we now concentrate the analysis on that part of the globe. Figure 8 shows the regression of the 0-120-day filtered streamfunction at $650 \mathrm{hPa}$ onto the AEW activity index. The significant signal (gray shading, see section 2 for details) is dominant for the time lags preceding day 0 (the time at which AEW activity is maximum) and mostly disappears after about day +6 . From day -20 to about day -8 , a wave train of anomalies, alternatively anticyclonic and cyclonic, is seen over North America and the Atlantic, propagating slowly eastward. It takes about 12 days for the anticyclonic anomaly in the middle of the Atlantic at day -20 to reach the western Mediterranean, giving an approximate wave period of 24 days. When the anomalies reach Europe, their direction of propagation appears to be refracted southward. From day -8 to day 0 , the dominant signal is a southward-propagating tripole over western Europe, the Mediterranean, and northern Africa. By day 0 , a positive anomaly covers the Mediterranean and the negative anomaly ahead has almost reached the area of Lake Chad, near the upstream part of the AEJ. This pattern has reversed phase between day -8 and day 0 , giving a period of about 16 days, which is shorter than the 24 days previously evaluated over the Atlantic. The sequence of events described above from the standard simulation can consistently be observed in the simulation where the Southern Hemisphere is nudged and in the simulation nudged over Asia.

The choice of the 650 -hPa level to show these features is a compromise because the signal over the Atlantic is stronger at upper levels, while the Mediterranean-north African tripole is stronger at lower levels; $650 \mathrm{hPa}$ also coincides with the AEJ maximum. Figure 9 shows the same regression for the $650-\mathrm{hPa}$ zonal wind, which is clearly collocated with meridional gradients of the streamfunction shown previously in Fig. 8. A modification of the upstream AEJ is revealed with anomalies of up to $1 \mathrm{~m} \mathrm{~s}^{-1}$. This can be traced back to the influence of the southward-propagating tripole, which in turn has its origins over the North Atlantic. The question remains of how these types of precursor fit into the existing conceptual framework for the initiation of AEWs, and how these model results compare with observations. This is discussed next.

\section{c. Comparison with observed AEW activity as seen in NCEP-2 data}

As already seen in Figs. 4-6, the model produces AEWs with realistic structure and also intraseasonal variability, or intermittency, despite the lack of convection in the model. But to what extent do the precursors diagnosed in the model correspond to observed precursors? Leroux et al. (2010) performed a similar regression with NCEP-2 data on the same AEW index. They found 1) a local reinforcement of convection in the upstream part of the AEJ 2 days prior to the maximum in AEW activity, 2) a reinforcement of the AEJ itself in its upstream part preceding the wave events, and 3) a shift-reinforcement of the AEJ in its downstreamnorthern part following the wave events, interpreted as a feedback effect of the AEWs on the jet. It is interesting to extend their analysis in time and space to compare with our modeling study.

Figure 10 shows the NCEP-2 June-September daily streamfunction at $650 \mathrm{hPa}$ regressed for different time lags onto the observed AEW activity index (to be compared with Fig. 8 for the model). The observations also have a wave train of anomalies preceding the enhanced 


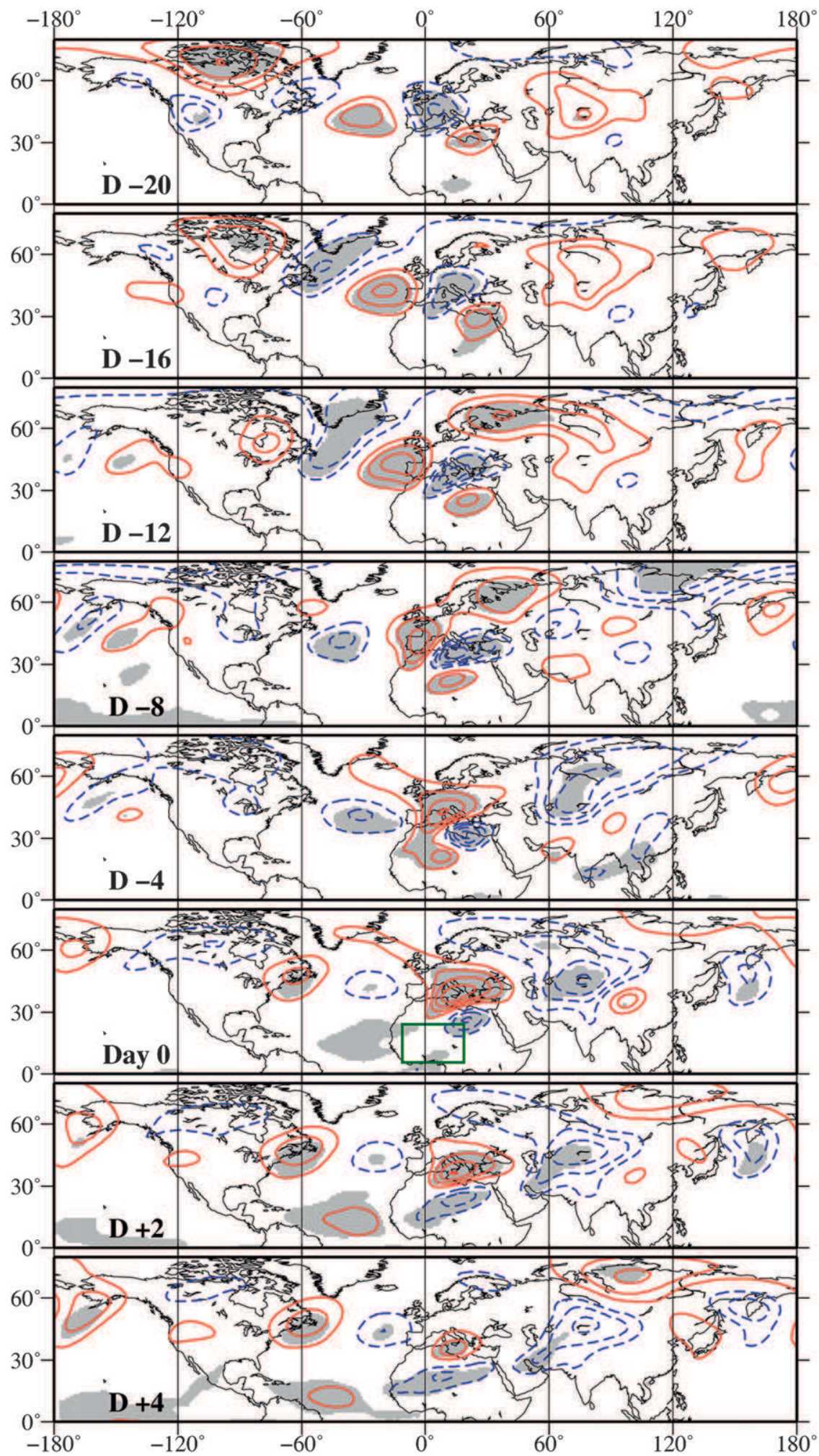

FIG. 8. Contours show the lag regression of the 0-120-day filtered streamfunction from the standard simulation at $650 \mathrm{hPa}$ onto the corresponding AEW activity index (see text) from (top to bottom) lag day -20 to lag day +6 every 2 days. Contours are every $1.5 \times 10^{5} \mathrm{~m}^{2} \mathrm{~s}^{-2}$; negative values dashed, and zero contour omitted. Gray shading shows where the signal passed the significance test at the $95 \%$ level (see section 2 ). The lat-lon area at day 0 displayed is used to calculate the AEW index. 


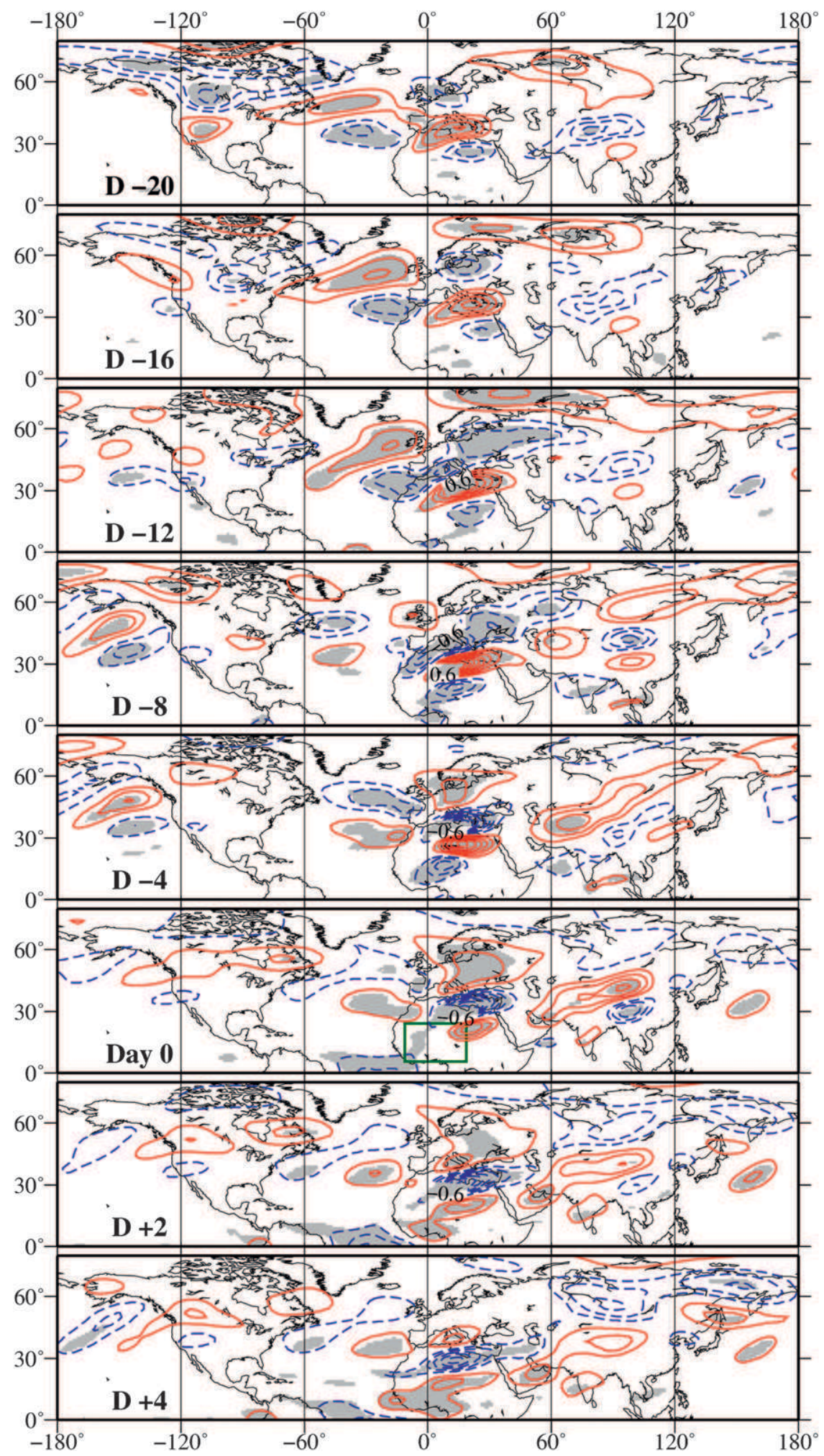

FIG. 9. As in Fig. 8, but for the 0-120-day filtered zonal wind from the standard simulation at $650 \mathrm{hPa}$. Contours are every $0.15 \mathrm{~m} \mathrm{~s}^{-1}$. 


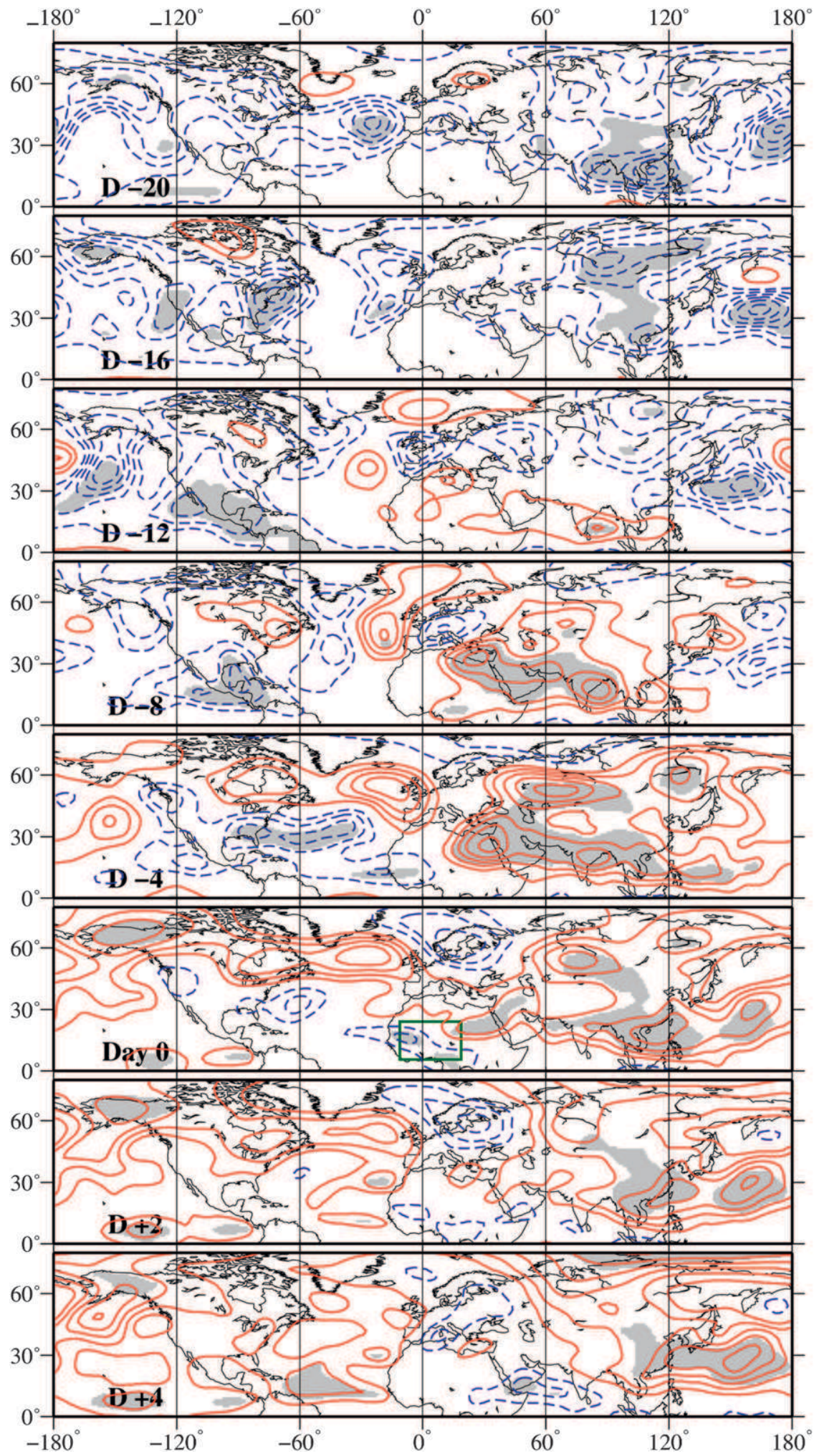

FIG. 10. As in Fig. 8, but for the 0-120-day filtered streamfunction from the June-September 1979-2006 NCEP-2 data at $650 \mathrm{hPa}$. Contours are every $1.2 \times 10^{5} \mathrm{~m}^{2} \mathrm{~s}^{-2}$. 
AEW wave activity, but the signal is clearly much weaker than in the model, barely achieving statistical significance over most of the domain for most time lags. Enhanced intraseasonal AEW activity is preceded by positive streamfunction in the North Atlantic and also over the eastern Mediterranean. The latter signal at least appears consistent with the model results, but there is only a relatively weak equivalent to the upstream wave train precursor seen in the model for longer lead times, with somewhat different phasing.

Figure 11 shows the regression of the NCEP-2 zonal wind at $650 \mathrm{hPa}$ (to be compared with Fig. 9 for the model). The signal from day -8 to day +4 is identical to that shown in Leroux et al. (2010): a reinforcement of the upstream AEJ followed by a dipole of east-west elongated anomalies across the West African coast, indicating a northward shift of the downstream part of the AEJ, possibly as a result of the feedback of the developing AEWs. For longer lead times, a tripole of eastwest elongated anomalies can also be seen over Europe (negative), the Mediterranean (positive), and northern Africa (negative) from about day -12 to day -6 , moving very slowly southward. The phasing for a given lead time is in near quadrature with the model result, which leads the observations and where the signal is also stronger and more persistent. Nevertheless, in both cases there are large anomalies that propagate into the AEJ jet region from the north in the days leading up to a strengthening of the AEW activity.

Longer-range precursors diagnosed from the reanalysis are weaker and less significant than those seen in the model, although there are some features in common. It is perhaps to be expected that a simulation in perpetualseason mode with time-independent diabatic forcing and free from convective noise would generate a clearer signal than can be observed in reality. The importance of the seasonal cycle remains to be investigated and would require further model development.

Finally, we note the similarity between our results and those of Chauvin et al. (2010), who suggest a possible modulation of AEW activity by a similarly evolving midlatitude wave train, in a composite study based on an index related to the variation in the Saharan heat low. Although our results are not directly comparable with theirs because of differences in the technique and the basis for their composites (low-level temperature), we also see that the wave train patterns detected here in both the model and observations have some influence on the low-level temperature over northern Africa (not shown). It thus appears that much of the variability over the whole of northern Africa is highly influenced by the extratropics, as has been observed in many other regions of the tropics and subtropics.

\section{Discussion and conclusions}

Many of the studies cited in the introduction approach the question of the origin and intermittency of AEWs, focusing on the region of AEW activity itself, concentrating on the properties of the AEJ or the influence of convection. In this paper we have explored the possibility of remote influences.

We have used a dry global atmospheric model forced by a constant term derived from the observations to perform GCM-like 4000-day summertime simulations. In this way the importance of remote influences could be isolated in a context free from convective feedback but retaining transient dynamical forcing. The model is able to simulate a realistic global climatology and mean state over West Africa, including the mean AEJ. On the global scale, transient activity is also relatively well simulated, albeit at a reduced amplitude compared to observations. The dry model is also able to produce realistic AEWs with an intermittency in wave activity comparable to observations. A set of experiments in which the transients are artificially suppressed in selected remote areas demonstrates that the simulated AEWs are not produced locally on an unstable AEJ but instead by direct interaction with the midlatitude North Atlantic storm track. Peaks in AEW activity in the model are preceded by an upper-level wave train over the Atlantic in the midlatitudes and a southward-propagating dipole in the flow over North Africa, accompanied by an easterly wind anomaly at the level of the AEJ.

With this study, we have extended the range of processes investigated up to now with the same dry model (Hall et al. 2006; Thorncroft et al. 2008; Leroux and Hall 2009) in relation to AEW activity. Our results again support the idea that AEWs rely on the existence of a finite-amplitude initial perturbation and do not arise locally from the instability of the AEJ alone. They demonstrate that, without convection at all in the system, it is still possible to trigger intermittent AEWs through dynamical interactions with the midlatitude Atlantic transient activity. The AEWs simulated in this study, although still only half the strength of observed waves, are nevertheless stronger than the AEWs that could be triggered in previous modeling studies where a convective-type heating perturbation of reasonable amplitude was applied locally in the jet entrance on a fixed climatological basic state from the observations (Thorncroft et al. 2008). This discrepancy in wave amplitude is confirmed when the same heating perturbation experiment as in Thorncroft et al. (2008) is repeated using the mean state of our GCM standard simulation instead of their observed climatological basic state. The way AEWs are initiated through interaction with the 


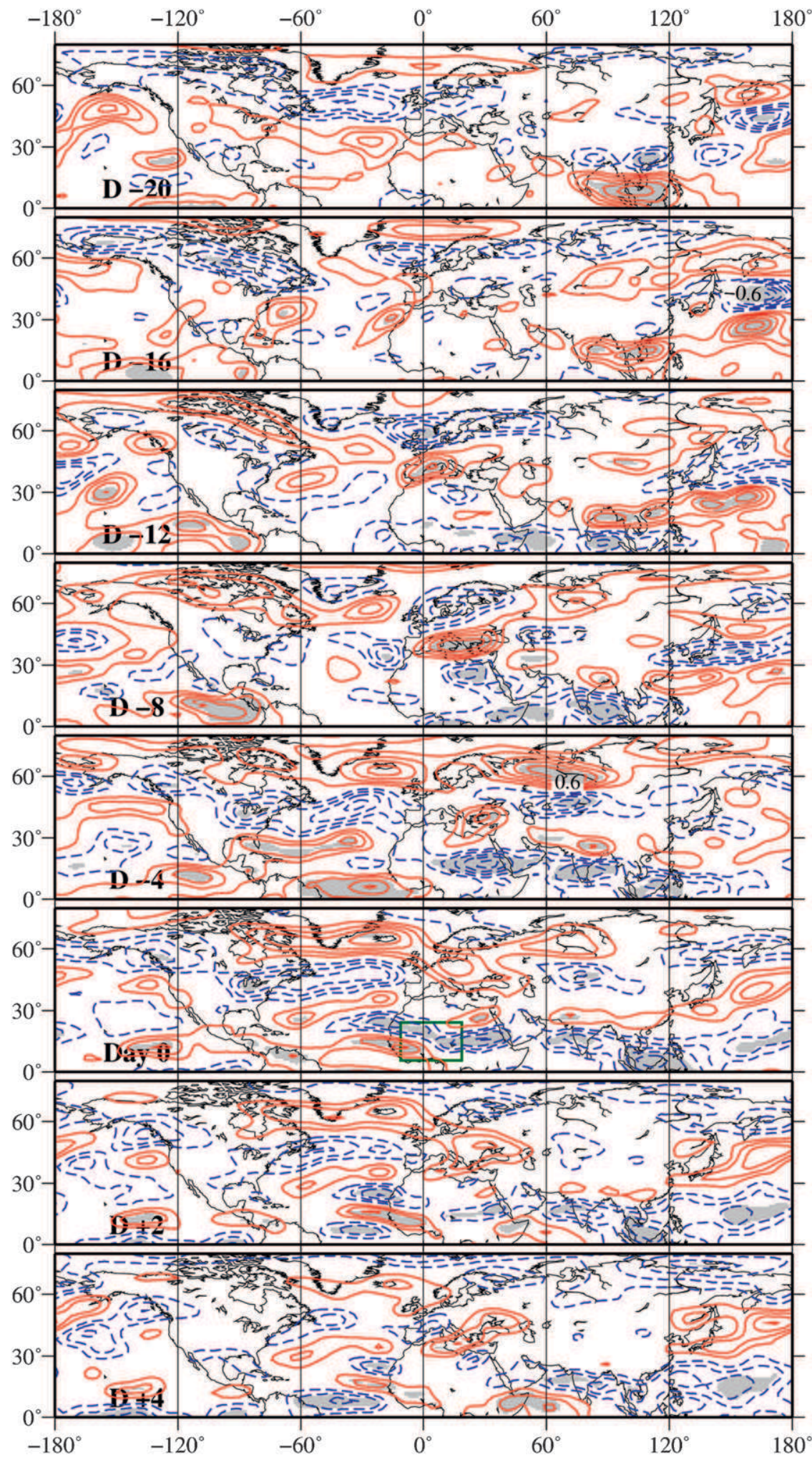

FIG. 11. As in Fig. 8, but for the 0-120-day filtered zonal wind from the standard simulation at $650 \mathrm{hPa}$. Contours are every $0.12 \mathrm{~m} \mathrm{~s}^{-1}$. 
midlatitudes in the dry GCM thus appears to be a more efficient mechanism (in term of the wave amplitude) than the convective triggering previously tested.

In conclusion, using a simple modeling approach, we have identified the possibility of a potentially important remote influence on the origin and intermittency of AEWs. The model is clearly at least as sensitive to this remote influence as it is to local triggering by convective heating, and both these mechanisms are far more effective than growth by instability alone in a realistic context. Observational evidence support the idea that a similar remote influence could occur in the real world, in addition to the convective triggering already considered by the previous literature. The intermittency of observed AEWs is likely to result from the sum of these different influences, which the model conveniently allows us to examine separately. The question of the relative importance of these different mechanisms for real waves, and their potential interaction, clearly remains to be investigated further. More work is needed to separate the relevant time scales, to differentiate between the importance of remote influence on the waves themselves and/or on the environment (the AEJ), and to investigate the importance of the seasonal cycle. We are pursuing such an investigation, and hope that our approach will inspire similar experiments with more comprehensive models and comparison with observations.

Acknowledgments. We thank the two reviewers for reading our manuscript and for making helpful comments and suggestions. This work was initiated as part of the African Monsoon Multidisciplinary Analyses program (www.amma-international.org) when Stephanie Leroux was based at the Laboratoire d'Étude des Transferts en Hydrology et Environnement, Université de Grenoble, France. The last part of the work was achieved at the Earth System Research Laboratory, NOAA, Boulder, Colorado, where Stephanie Leroux was funded by a National Research Council postdoctoral fellowship.

\section{REFERENCES}

Avila, L., and R. Pasch, 1992: Atlantic tropical systems of 1991 Mon. Wea. Rev., 120, 2688-2696.

Berry, G. J., and C. Thorncroft, 2005: Case study of an intense African easterly wave. Mon. Wea. Rev., 133, 752-766.

Burpee, R., 1972: The origin and structure of easterly waves in the lower troposphere of North Africa. J. Atmos. Sci., 29, 77-90.

Carlson, T. N., 1969: Synoptic histories of three African disturbances that developed into Atlantic hurricanes. Mon. Wea. Rev., 97, 256-276.

Chauvin, F., R. Roehrig, and J.-P. Lafore, 2010: Intraseasonal variability of the Saharan heat low and its link with midlatitudes. J. Climate, 23, 2544-2561.
Cornforth, R. J., B. J. Hoskins, and C. D. Thorncroft, 2009: The impact of moist processes on the African easterly jet-African easterly wave system. Quart. J. Roy. Meteor. Soc., 135, 894913.

Diedhiou, A., S. Janicot, A. Viltard, P. de Felice, and H. Laurent, 1999: Easterly wave regimes and associated convection over West Africa and tropical Atlantic: Results from the NCEP/ NCAR and ECMWF reanalyses. Climate Dyn., 15, 795-822.

Duchon, C. E., 1979: Lanczos filtering in one and two dimensions. J. Appl. Meteor., 18, 1016-1022.

Duvel, J.-P., 1990: Convection over tropical Africa and the Atlantic Ocean during northern summer. Part II: Modulation by easterly waves. Mon. Wea. Rev., 118, 1855-1869.

Fink, A. H., and A. Reiner, 2003: Spatiotemporal variability of the relation between African easterly waves and West African squall lines in 1998 and 1999. J. Geophys. Res., 108, 4332-4348.

Grist, J. P., 2002: Easterly waves over Africa. Part I: The seasonal cycle and contrasts between wet and dry years. Mon. Wea. Rev., 130, 197-211.

Gu, G., R. F. Adler, G. J. Huffman, and S. Curtis, 2003: Summer synoptic-scale waves over West Africa observed by TRMM. Geophys. Res. Lett., 30, 1729, doi:10.1029/2003GL017402.

$-, \ldots, \ldots$, and ——, 2004: African easterly waves and their association with precipitation. J. Geophys. Res., 109, D04101, doi:10.1029/2003JD003967.

Hall, N. M. J., 2000: A simple GCM based on dry dynamics and constant forcing. J. Atmos. Sci., 57, 1557-1572.

2004: The atmospheric response to boundary forcing and the use of diagnostic models. J. Phys. IV, 121, 125-137.

, and J. Derome, 2000: Transience, nonlinearity, and eddy feedback in the remote response to El Niño. J. Atmos. Sci., 57, 3992-4007.

— G. N. Kiladis, and C. D. Thorncroft, 2006: Three-dimensional structure and dynamics of African easterly waves. Part II: Dynamical modes. J. Atmos. Sci., 63, 2231-2245.

Hoskins, B. J., 1983: Dynamical processes in the atmosphere and the use of models. Quart. J. Roy. Meteor. Soc., 109, 1-21. , and A. J. Simmons, 1975: A multi-layer spectral model and the semi-implicit method. Quart. J. Roy. Meteor. Soc., 101, 637-655.

Hsieh, J.-S., and K. H. Cook, 2008: On the instability of the African easterly jet and the generation of African waves: Reversals of the potential vorticity gradient. J. Atmos. Sci., 65, 2130-2151.

Kanamitsu, M., W. Ebisuzaki, J. Woollen, S.-K. Yang, J. J. Hnilo, M. Fiorino, and G. L. Potter, 2002: NCEP-DOE AMIP-II Reanalysis (R-2). Bull. Amer. Meteor. Soc., 83, 1631-1643.

Kiladis, G. N., C. D. Thorncroft, and N. M. J. Hall, 2006: Threedimensional structure and dynamics of African easterly waves. Part I: Observations. J. Atmos. Sci., 63, 2212-2230.

Leroux, S., and N. M. J. Hall, 2009: On the relationship between African easterly waves and the African easterly jet. J. Atmos. Sci., 66, 2303-2316.

— - - and G. N. Kiladis, 2010: A climatological study of transient-mean-flow interactions over West Africa. Quart. J. Roy. Meteor. Soc., 136, 397-410.

Lin, H., and J. Derome, 1996: Changes in predictability associated with the PNA pattern. Tellus, 48A, 553-571.

— G. Brunet, and J. Derome, 2007: Intraseasonal variability in a dry atmospheric model. J. Atmos. Sci., 64, 2422-2441.

Livezey, R. E., and W. Y. Chen, 1983: Statistical field significance and its determination by Monte Carlo techniques. Mon. Wea. Rev., 111, 46-59. 
Marshall, J., and F. Molteni, 1993: Toward a dynamical understanding of planetary-scale flow regimes. J. Atmos. Sci., 50, $1792-1818$

Mekonnen, A., C. D. Thorncroft, and A. R. Aiyyer, 2006: Analysis of convection and its association with African easterly waves. J. Climate, 19, 5405-5421.

Nicholson, S. E., A. I. Barcilon, and M. Challa, 2008: An analysis of West African dynamics using a linearized GCM. J. Atmos. Sci., 65, 1182-1203.

Roads, J. O., 1987: Predictability in the extended range. J. Atmos. Sci., 44, 3495-3527.

Roehrig, R., F. Chauvin, and J.-P. Lafore, 2011: 10-25-day intraseasonal variability of convection over the Sahel: A role of the Saharan heat low and midlatitudes. J. Climate, in press.

Ruti, P., and A. Dell'Aquila, 2010: The twentieth century African easterly waves in reanalysis systems and IPCC simulations, from intra-seasonal to inter-annual variability. Climate Dyn., 35, 1099-1117.

Sardeshmukh, P. D., and P. Sura, 2007: Multiscale impacts of variable heating in climate. J. Climate, 20, 5677-5695.

Schubert, W. H., P. E. Ciesielski, D. E. Stevens, and H.-C. Kuo, 1991: Potential vorticity modeling of the ITCZ and the Hadley circulation. J. Atmos. Sci., 48, 1493-1509.

Simmons, A. J., and D. M. Burridge, 1981: An energy and angular-momentum conserving vertical finite-difference scheme and hybrid vertical coordinates. Mon. Wea. Rev., 109, 758-766.

Thorncroft, C. D., 1995: An idealized study of African easterly waves. III: More realistic basic states. Quart. J. Roy. Meteor. Soc., 121, 1589-1614.

_ and B. Hoskins, 1994: An idealized study of African easterly waves. I: A linear view. Quart. J. Roy. Meteor. Soc., 120, 953 982.

_- and M. Blackburn, 1999: Maintenance of the African easterly jet. Quart. J. Roy. Meteor. Soc., 125, 763-786.

_ and K. Hodges, 2001: African easterly wave variability and its relationship to Atlantic tropical cyclone activity. J. Climate, 14, 1166-1179.

_, N. Hall, and G. Kiladis, 2008: Three-dimensional structure and dynamics of African easterly waves. Part III: Genesis. J. Atmos. Sci., 65, 3596-3607.

Vizy, E. K., and K. H. Cook, 2009: A mechanism for African monsoon breaks: Mediterranean cold air surges. J. Geophys. Res., 114, D01104, doi:10.1029/2008JD010654.

Wilks, D. S., 2005: Statistical Methods in the Atmospheric Sciences: An Introduction. International Geophysics Series, Vol. 91, Academic Press, 467 pp.

Yasui, S., and M. Watanabe, 2010: Forcing processes of the summertime circumglobal teleconnection pattern in a dry AGCM. J. Climate, 23, 2093-2114. 